Article

\title{
Genetic Diversity of Local Peach (Prunus persica) Accessions from La Palma Island (Canary Islands, Spain)
}

\author{
Verónica Pérez ${ }^{1,2}$, Nerea Larrañaga ${ }^{1,3}$, Donia Abdallah ${ }^{4}$, Ana Wünsch ${ }^{5,6}$ (D) and \\ José I. Hormaza ${ }^{1, *}$ \\ 1 Subtropical Fruit Crops Department, Instituto de Hortofruticultura Subtropical y Mediterránea La \\ Mayora (IHSM La Mayora-CSIC-UMA), 29750 Algarrobo-Costa, 29750 Málaga, Spain; \\ veronica@ipna.csic.es (V.P.); nlarranaga@eelm.csic.es (N.L.) \\ 2 Laboratorio de Agrobiología Juan José Bravo Rodríguez (Cabildo Insular de La Palma), \\ Unidad Técnica del IPNA-CSIC. S/C La Palma. 38700 Canary Islands, Spain \\ 3 IMAREFI, University of Guadalajara, 45110 Jalisco, Mexico \\ 4 Département de Biologie, Faculté des Sciences de Tunis, Université Tunis el Manar, 2092 Tunis, Tunisia; \\ abdallahdonia@yahoo.fr \\ 5 Unidad de Hortofruticultura. Centro de Investigación y Tecnología Agroalimentaria de Aragón (CITA). \\ Avda. Montañana 930, 50059 Zaragoza, Spain; awunsch@aragon.es \\ 6 Instituto Agroalimentario de Aragón-IA2 (CITA-Universidad de Zaragoza), 50013 Zaragoza, Spain \\ * Correspondence: ihormaza@eelm.csic.es; Tel.: +34-952-548-990
}

Received: 17 February 2020; Accepted: 20 March 2020; Published: 25 March 2020

\begin{abstract}
Peach (Prunus persica) is an economically important temperate fruit crop due to its edible fruits. Due to the need to develop new varieties better adapted to climate change, it is of great interest to find germplasm adapted to warmer conditions, such as those found in the Canary Islands. Peach was an important crop during the last century in one of those islands (La Palma), but its cultivation has been abandoned in recent years. Currently, commercial production is relict and isolated trees are relegated to family orchards with little management. With the objective to characterize and prevent the loss of local varieties of this crop, peach trees were sampled along La Palma. A total of 89 local peach accessions were prospected and analyzed with 10 single-sequence repeat (SSR) loci, which permitted 28 different genotype profiles to be detected. These genotypes were compared to 95 Spanish peach landraces conserved in an ex situ collection, and 26 additional samples from eight different countries. Results showed that the peach genetic diversity found in La Palma was low. In addition, a relation between La Palma samples and other Spanish peaches was observed, which could indicate the arrival of genetic material from the Iberian Peninsula and subsequent intercrossing and local selection of the genotypes more adapted to the subtropical climate of the island. The population structure reflects a grouping of the samples based on fruit type and geographic origin.
\end{abstract}

Keywords: genetic diversity; germplasm; home gardens; microsatellites; simple sequence repeats (SSR)

\section{Introduction}

Peach (Prunus persica (L.) Batsch) is a diploid temperate fruit tree $(2 n=2 x=16)$, with relevant commercial, ornamental, and economic value, that belongs to the genus Prunus in the subfamily Prunoideae of the Rosaceae. Other woody perennial crops of interest in the genus include, among others, almond (P. dulcis (Mill.) D.A. Webb), European (P. domestica L.) and Japanese (P. salicina Lindl.) plums, European (P. armeniaca L.) and Japanese (P. mume Siebold and Zucc.) apricots, or sweet (Prunus avium L.) and sour (Prunus cerasus L.) cherries. Peach is native to China where its domestication and 
cultivation could have occurred for more than 4000 years [1,2], although more recent studies suggest an older domestication that could be dated back to at least 7500 years ago [3,4]. Currently, peach is a widespread crop in temperate and subtropical regions of the world; about 25 million tons were produced in 2018, mainly in China, which accounts for more than half of the world's production, followed by Italy, Greece, Spain, Turkey, the USA, and Iran [5]. Peach is a self-compatible species [6,7].

The long cultivation period has led to significant peach diversification [8-10], showing a high diversity in China. However, the increasing use of commercial varieties is eroding this diversity [11,12], as in other Prunus species [13]. Consequently, studies on peach genetic diversity [14,15] and other woody perennial species have become important in the last few years in order to conserve interesting germplasm for future generations [16]. Local varieties have the advantage of their adaptation to specific soil and climatic conditions and could be a gene reservoir to improve commercial varieties [17]. A key example is the current scenario of climate change in which varieties adapted to warmer temperatures, especially in winter and spring, can be of high interest to cope with a future of lower chilling hours in temperate regions. Thus, in this study, we analyzed peach genetic diversity in La Palma, the northwesternmost island of the Canary Islands (Figure 1), part of the Macaronesia, a group of five North Atlantic archipelagos, which includes Azores, Madeira, the Savage Islands, Canary Islands, and Cabo Verde, which extends from southwestern Europe to northwestern Africa. La Palma has a subtropical-Mediterranean climate and an extension of $708 \mathrm{~km}^{2}$ that range from sea level to 2426 masl. After the Spanish arrival to America in 1492, La Palma became the most important harbor in the Canaries in the commercial route between mainland Europe and the New World [18]. This continued up to the last century with intense exchange of people and goods with different Central and South American countries, especially from Cuba and Venezuela [19-21]. As a result, the island presents an interesting diversity of plant materials from diverse origins.
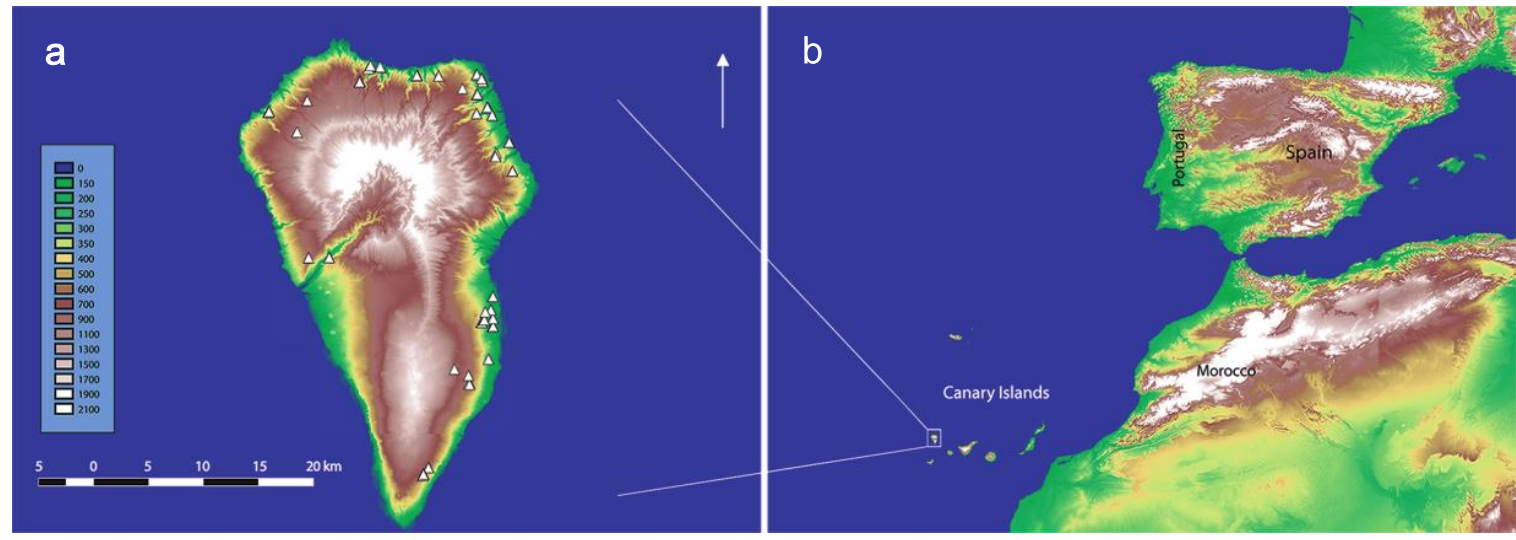

Figure 1. Elevation map of La Palma showing the spatial distribution of the peach trees sampled (white triangles) (a). Geographical localization of Canary Islands and La Palma (b).

The traditional cultivation of peach in La Palma was rainfed and mostly for canning, with commercial importance mainly at the end of the XIX century and beginning of the XX century [22]. During this time, six canneries were open, and production was mainly exported to Cuba and other ports in the Antilles. The diversity of peach varieties in the Canary Islands and La Palma was already reported by Viera y Clavijo more than 100 years ago [23], and, later, in the inventory of cultivars of different fruit tree crops conducted in Spain in the 1950s [24]. However, a long period of drought, marketing problems, and fruit fly pests resulted in a critical time for this crop between 1915 and 1920 [22]. Currently, most peach trees in La Palma remain in family gardens or neglected in old orchards. The abrupt orography of the island and marketing difficulties have limited the development of a technified and intensive peach production. As a result, annual peach production in the Canaries is 1.85 tons, of which just 0.95 belong to La Palma [25], increasingly becoming a minor crop at risk of disappearance. 
In order to reverse the threat of losing valuable peach genetic resources, La Palma peach diversity was analyzed in this work with 10 microsatellite loci. Microsatellite or single-sequence repeat (SSR) markers are extensively used in plants because of their co-dominance, stability, ease of application, and high sensibility [26]. They have been widely used in diversity studies of peach $[10,11,14,15,27-31]$. The local La Palma accessions were compared to a Spanish reference peach collection and 26 additional foreign accessions, with the goal of having a broader view of the genetic diversity of La Palma peach germplasm. Thus, the main objectives of this work are (1) molecular characterization of local peach varieties from La Palma, (2) comparison of the relationships with peach accessions from other geographic origins, and (3) optimization of the conservation of this fruit crop in La Palma.

\section{Materials and Methods}

\subsection{Plant Material}

This study was carried out on 89 P. persica peach accessions sampled at different places on La Palma island from 126 to 993 masl (Figure 1; Table S1). Peach samples were collected from young leaves in spring (March to April) mainly in home gardens and isolated trees; all samples were georeferenced with the MapFactor GPS Navigator Maps mobile app. Samples were preserved in silica gel until DNA extraction for further molecular analyses. In addition, peach DNA from 95 local Spanish peach genotypes and 26 accessions from other countries (Argentina, Bolivia, Brazil, Canada, France, Italy, South Africa, and Vietnam) mainly maintained at "CITA de Aragon" in Zaragoza, Spain, was used in this work (Table S2).

The samples analyzed were divided into three groups or populations: "La Palma samples," "Spanish collection," and a fictitious population with the samples from the other countries named "Other countries".

\subsection{DNA Extraction and PCR Amplification}

Plant DNA extraction was performed from silica-gel-dried young leaves following a modified cetyl trimethylammonium bromide (CTAB) method for Prunus [32], using extraction buffer with $350 \mathrm{mM}$ Sorbitol, $100 \mathrm{mM}$ Tris- $\mathrm{HCl}, 6.4 \mathrm{mM}$ EDTA, and $0.1 \% \mathrm{NaHSO}_{3} \mathrm{pH} 7.5$, and nuclei lysis buffer with $200 \mathrm{mM}$ Tris- $\mathrm{HCl}, 64 \mathrm{mM}$ EDTA, $2 \mathrm{M} \mathrm{NaCl}, 2 \% \mathrm{CTAB}$, and 5\% N-lauryl sarcosine. Genomic DNA was amplified with 10 SSR loci, previously used by Wünsch et al. [14] (Table 1). PCR amplification was performed with $16 \mathrm{mM}\left(\mathrm{NH}_{4}\right)_{2} \mathrm{SO}_{4}, 67 \mathrm{mM}$ Tris- $\mathrm{HCl} \mathrm{pH} \mathrm{8.8,} \mathrm{0.01 \%} \mathrm{Tween-20,} 20.3 \mathrm{mM} \mathrm{MgCl}$, $0.1 \mathrm{mM}$ of each dNTP, $0.3 \mu \mathrm{M}$ of each primer, $20 \mathrm{ng}$ of genomic DNA, and 1 unit of BioTaq ${ }^{\mathrm{TM}}$ DNA polymerase (Bioline, London, UK) in a final volume of $15 \mu$ l. Forward primers were labelled with WellRed fluorescent dyes on the 5' end (Sigma-Aldrich, St. Louis, MO, USA). Reactions were carried out on a thermocycler (Bio-Rad Laboratories, Hercules, CA, USA) using the following temperature profile: An initial step of $2 \mathrm{~min}$ at $94{ }^{\circ} \mathrm{C}, 35$ cycles of $45 \mathrm{~s}$ at $94{ }^{\circ} \mathrm{C}, 45 \mathrm{~s}$ at $57^{\circ} \mathrm{C}$, and $1 \mathrm{~min}$ at $72{ }^{\circ} \mathrm{C}$, and a final step of $5 \mathrm{~min}$ at $72^{\circ} \mathrm{C}$. $\mathrm{PCR}$ products were separated by capillary electrophoresis in a CEQ ${ }^{\mathrm{TM}}$ 8000 capillary DNA analysis system (Beckman Coulter, Fullerton, CA, USA).

\subsection{Fingerprinting and Genetic Diversity Analyses}

Georeferenced sampled plots from La Palma were included in a digital elevation model $(1 \times 1 \mathrm{~m})$ using GIS software [33]. The La Palma altitude raster map was downloaded from www.idecanarias.es. The resulting map is shown in Figure 1.

To differentiate La Palma peach genotypes and avoid synonymies and homonymies, the molecular data of the 89 samples prospected were analyzed using the NTSYS software [34]. The Dice coefficient [35] was used to generate a similarity matrix, and an unweighted pair group method with arithmetic mean (UPGMA) cluster analysis was performed using that matrix. Only the genotypes from La Palma that showed different amplification profiles were used for the global peach comparison. 
Genetic diversity between populations (La Palma, Spanish collection, and Other countries collection) was estimated using the average number of alleles per locus, the number of polymorphic markers, the observed heterozygosity $\left(\mathrm{H}_{\mathrm{o}}\right)$, the expected heterozygosity $\left(\mathrm{H}_{\mathrm{e}}\right)$, Wright's fixation index (Fis), Nei's Fst pairwise matrix, and the private alleles. The number of alleles, the genetic indices $\left(\mathrm{H}_{0}\right.$, $\left.\mathrm{H}_{\mathrm{e}}\right)$, effective number of alleles $\left[\left(\mathrm{N}_{\mathrm{e}}=1 /\left(1-\mathrm{H}_{\mathrm{e}}\right)\right]\right.$, and Wright's fixation index $\left(\mathrm{F}=1-\mathrm{H}_{0} / \mathrm{H}_{\mathrm{e}}\right)[36]$, were also calculated per locus. Genetic diversity indices were calculated with R Version 3.4.0 using adegenet $[37,38]$ and PopGenReport $[39,40]$ packages. To stablish the relations between the samples from La Palma and the rest of the accessions, a neighbor joining (NJ) analysis with the Dice similarity matrix [34] was performed with the NTSYS software (Exeter Software, Stauket, NY, USA). The resulting tree was plotted with FigTree software [41]. Genetic structure between populations was estimated using the Bayesian clustering algorithm implemented in STRUCTURE software ver. 2.3.4 [42]. This analysis was performed five times with the samples arranged following the same order obtained with the NJ analysis. The parameter set used was 10 interactions of 200,000 Markov Chain Monte Carlo (MCMC) generations with a burn-in period of 20,000 generations [13] for $K$ from 1 to 10 . The $K$ probability was also analyzed according to Evanno et al. [43] using Structure Harvester v.0.6.94 [44]. Interactions in STRUCTURE were combined using the large $K$ greedy algorithm from the program CLUMPP Version 1.1.2 [45] and the representation was performed with the program distruct Version 1.1 [46].

Table 1. Number of alleles per locus, observed $\left(\mathrm{H}_{\mathrm{o}}\right)$ and expected $\left(\mathrm{H}_{\mathrm{e}}\right)$ heterozygosities, effective number of alleles $\left(\mathrm{N}_{\mathrm{e}}\right)$, and Wright's fixation index $(\mathrm{F})$ of 148 peach genotypes using 10 SSR microsatellite markers.

\begin{tabular}{cccccc}
\hline SSR Locus & Number of Alleles & Ho & He & Ne & F \\
\hline Pchgms-3 $^{\text {a }}$ & 9 & 0.372 & 0.589 & 2.437 & 0.370 \\
UDP96-001 $^{\mathrm{b}}$ & 8 & 0.150 & 0.627 & 2.683 & 0.761 \\
UDP96-003 $^{\mathrm{b}}$ & 6 & 0.149 & 0.241 & 1.318 & 0.383 \\
UDP96-008 $^{\mathrm{b}}$ & 4 & 0.149 & 0.189 & 1.234 & 0.216 \\
UDP96-018 $^{\mathrm{b}}$ & 4 & 0.345 & 0.508 & 2.034 & 0.322 \\
UDP98-406 $^{\mathrm{b}}$ & 6 & 0.108 & 0.160 & 1.190 & 0.323 \\
UDP96-015 $^{\mathrm{b}}$ & 8 & 0.338 & 0.649 & 2.848 & 0.479 \\
UDP98-407 $^{\mathrm{b}}$ & 5 & 0.128 & 0.400 & 1.666 & 0.679 \\
UDP98-416 $^{\mathrm{c}}$ & 5 & 0.101 & 0.348 & 1.533 & 0.709 \\
CPPCT6 $^{\mathrm{d}}$ & 4 & 0.142 & 0.389 & 1.637 & 0.635 \\
\hline
\end{tabular}

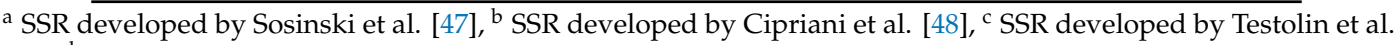
[29], d SSR developed by Aranzana et al. [49].

\section{Results}

\subsection{SSR Polymorphism and Molecular Characterization of La Palma Local Peach Accessions}

The analysis of the 89 samples of local peach accessions from La Palma, using 10 SSR loci, allowed the differentiation of 28 different genotype profiles (Table S1). Figure 2 shows the UPGMA tree obtained (Gent1-Gent28). Synonymies and homonymies were detected in the samples. Genetic profiles were represented by more than one sample in $35.7 \%$ of the cases, while $64.3 \%$ were represented by only one sample. The dendrogram showed five main clusters (indicated in the figure): Cluster I: This cluster included most of the samples. In this group, the name given by the farmers to varieties usually refers to the color of the flesh (mesocarp) of the fruit as yellow/white. Gent 1 represented $34.8 \%$ of all samples, being the most common genotype profile. Cluster II: 'Gent15-17' to 'Gent23-24' includes accessions with names referring to the white color of the fruits, although some accessions in this group were also referred to as yellow. Cluster III: Includes only one genotype, 'Amarillo Merollo,' referred to as yellow flesh in the name. Cluster IV is formed by two genotype profiles: One red (rojo) and another white (blanco). Finally, Cluster V is formed by only one sample, 'Venezolano,' which was clearly separated from the rest of the accessions. The name of this accession probably refers to its origin ('Venezuelan'). 


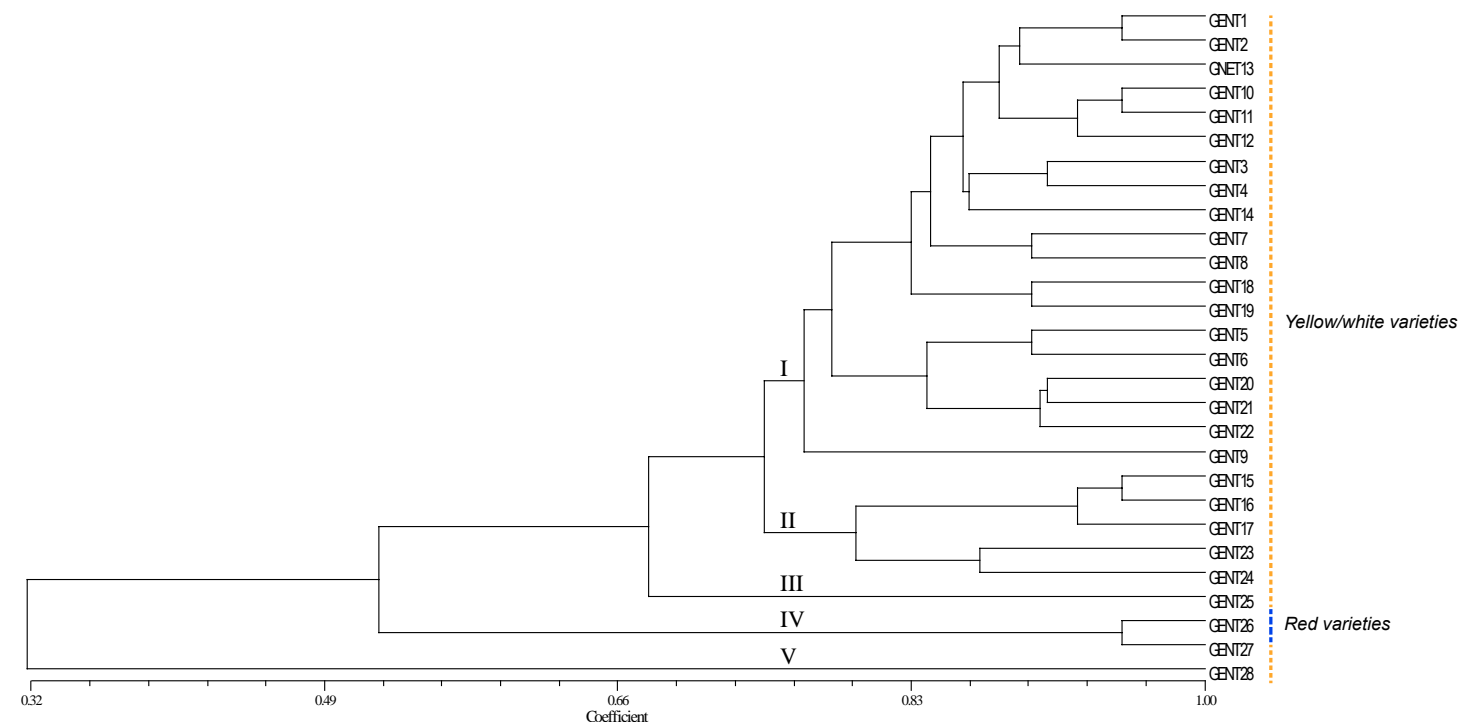

Figure 2. Unweighted pair group method with arithmetic mean (UPGMA) dendrogram of the 28 genetically different La Palma local peach genotypes using a similarity matrix generated by the Dice coefficient with 10 single-sequence repeat (SSR) loci. The dashed yellow line indicates varieties with yellow/white flesh, while the dashed blue line indicates varieties with red flesh.

3.2. Comparison of the SSR Polymorphism of La Palma Local Peach Varieties with Other Accessions from Spain and Additional Countries

The 10 SSR loci used 59 amplified fragments with a mean of 5.9 alleles per locus in all the accessions studied. The number of alleles per locus ranged between 4 (UDP96-008, UDP96-018, and СPPCT6) and 9 (Pchgms-3). The observed heterozygosity $\left(\mathrm{H}_{\mathrm{o}}\right)$ ranged from 0.10 (UDP98-416) to 0.37 (Pchgms-3), with a mean of 0.20 . The expected heterozygosity $\left(\mathrm{H}_{\mathrm{e}}\right)$ varied from 0.16 (UDP98-406) to 0.65 (UDP96-015), with a mean of 0.41 . The number of effective alleles (Ne) ranged from 1.19 (UDP98-406) to 2.83 (UDP96-015). Wright's fixation index $(F)$ that estimates the degree of allelic fixation ranged from 0.22 (UDP96-008) to 0.76 (UDP96-001) (Table 1).

The diversity indices for each group of accessions, La Palma (28 genotypes, after their characterization), Spanish peach collection (95 accessions), and other countries (26 accessions, from eight countries), are shown in Table 2. All the loci analyzed showed polymorphism in both the Spanish collection and the samples from other countries; in the samples from La Palma, one of the loci studied (UDP98-406) was monomorphic. The mean number of alleles per population was higher in the samples from other countries (4.7), followed by the samples from the Spanish collection (4.1), and the lowest polymorphism was observed in those from La Palma (3.2). The observed heterozygosity index was higher in the samples from the Spanish collection (0.23), followed by the samples from other countries (0.21), and the value was very low (0.07) for the samples from La Palma. The expected heterozygosity was higher than the observed heterozygosity in all three cases: 0.28 for La Palma samples, 0.34 for the Spanish collection, and 0.45 for other countries. The Fis index was 0.56 for the samples from other countries, 0.42 for the Spanish collection, and 0.73 for La Palma accessions. The pairwise Fst matrix was 0.02 for the Spanish collection and other countries, 0.04 for Spain and La Palma, and 0.09 for other countries and La Palma. The number of private alleles was higher for the accessions from other countries (11), followed by the Spanish population (6) and La Palma (5). The private alleles in La Palma samples appeared in 4 of the 28 different genotypes (14.3\%), and each of these alleles was only present in one sample. 
Table 2. Parameters of La Palma, Spain, and other countries (Argentina, Bolivia, Brazil, Canada, France, Italy, South Africa, and Vietnam) peach samples with the analysis with 10 microsatellite loci, including mean of number of alleles per loci, number of polymorphic loci, observed heterozygosity $\left(\mathrm{H}_{\mathrm{o}}\right)$, expected heterozygosity $\left(\mathrm{H}_{\mathrm{e}}\right)$, Fst and Wright's fixation index (Fis) statistic, and number of private alleles.

\begin{tabular}{cccccccc}
\hline Samples & $\begin{array}{c}\text { Sample } \\
\text { Size }\end{array}$ & $\begin{array}{c}\text { Mean } \mathbf{n}^{\circ} \text { of } \\
\text { Alleles/Locus }\end{array}$ & $\begin{array}{c}\mathbf{N}^{\circ} \text { of } \\
\text { Polymorphic } \\
\text { Loci }\end{array}$ & Ho & He & Fis & $\begin{array}{c}\mathbf{N}^{\circ} \text { of } \\
\text { Private } \\
\text { Alleles }\end{array}$ \\
\hline $\begin{array}{c}\text { La Palma } \\
\text { Spanish } \\
\text { collection }\end{array}$ & 28 & 3.2 & 9 & 0.075 & 0.280 & 0.732 & 5 \\
Other countries & 26 & 4.1 & 10 & 0.232 & 0.398 & 0.417 & 6 \\
\hline
\end{tabular}

${ }^{*}$ It is not in Hardy-Weinberg equilibrium.

\subsection{Genetic Relationships}

The NJ tree constructed from the Dice similarity matrix grouped samples in two main clusters (Figure 3). The first group has most of the samples, and only four samples were included in a second group: 'Binaced,' 'Comodin,' and 'Moret' from Spain and one accession from Vietnam. The main group was organized as follows. In the upper part, there was a big cluster with samples of the platycarpa type (flat peaches) together with other peaches, such as 'Cristalino' from Argentina, 'Silver Ray,' 'Silver Star,' and 'Vesubio' from Italy, and other accessions from the Spanish collection. Some accessions seem to be homonymies: 'CZ CN4' and 'Paraguayo T Robert,' 'Paraguayo Almudi' and 'Paraguayo Caspe,' and 'Maella' and 'Valdetormo BD.' Below this group, there are several groups: An upper part with mainly samples from other countries but also with accessions from the Spanish collection and La Palma ('Gent28,' 'Gent24,' and 'Gent23'). 'Gent28,' with the local name Venozolano, despite clustering together with 'Silver Splendid' from Italy, showed one of the longest branches. 'Gent24' also clustered close to Italian samples, and 'Gent23' showed homonymy with 'Keimoes' from South Africa. The following cluster grouped most of the Spanish collection and La Palma samples. In this group only, one sample from Bolivia and one from Italy were present. The genotypes 'Gent4,' 'Gent25,' 'Gen15,' 'Gent16,' and 'Gent17' grouped among samples of the Spanish collection. The genotypes 'Gent4' and 'Gent25' were in the same group as 'Evaisa,' 'Pavia Amarillo Tolosa,' and 'Tipo Campiel.' The genotypes 'Gen15', 'Gent16,' and 'Gent17' grouped with '7-2-B,' 'Sudanell-3,' and 'Duraznillo.' The rest of La Palma samples grouped together and related with 'Generoso,' 'Calanda Sonrosado,' and 'Amarillo Octubre' from the Spanish collection, except 'Gent13' that appeared alone. Finally, 'Gent26' and 'Gent27' were identified by farmers as red and white varieties, respectively, clustered with Spanish red varieties. The five homonymous samples assigned as 'Gent26' were named as 'Negra or 'Negra Palmera' by farmers; the word negra refers to a dark variety or red variety. In only one sample of this group, farmers referred to it as 'Blanco Mollar' (blanco is white in Spanish). 


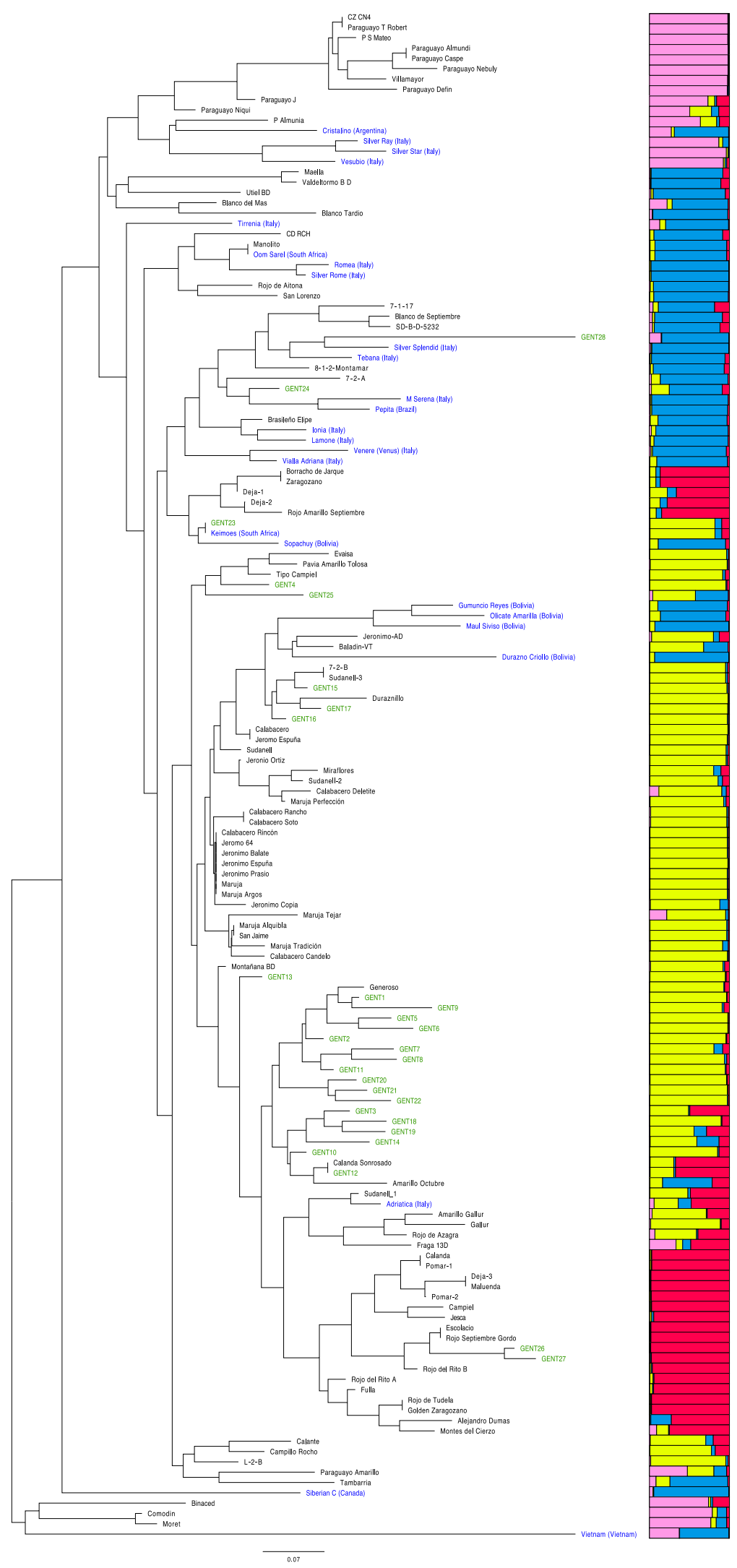

Figure 3. Neighbor joining (NJ) dendrogram with all the samples analyzed. Local samples from Spain (black), local samples from La Palma (green), and samples from other countries (blue). The dendrogram is related to the results obtained from STRUCTURE software with $\mathrm{k}=4$ populations. 


\subsection{Genetic Structure}

After NJ cluster analysis, the samples were ordered according to the results obtained and a Bayesian analysis using STRUCTURE software with $k$ from 1 to 10 populations, and 10 repetitions per $K$ were performed (Figure 4). The results obtained were analyzed with Evanno to find the best number of populations that was $k=4$ (Figure 4). The comparison between the NJ tree and the populations assigned by Evanno showed an apparent relationship between the samples and the groups established (Figure 3). According to this result, the three populations assigned first in this study: "La Palma samples," "Spanish collection," and "other countries" were organized as follows. A first population with flat peach varieties, a second population with samples from differences origins, a third population with mainly samples from the Spanish collection and La Palma, and a fourth population with the red varieties from La Palma and Spain mainland. When lower numbers of $k$ were used, flat peaches and red varieties were grouped together. In addition, when the number of $k$ was equal to or higher than five, La Palma samples were grouped as one population, separated from the Spanish collection. The fictional group of "other countries" was unstructured with 5 or a higher number of $k$.

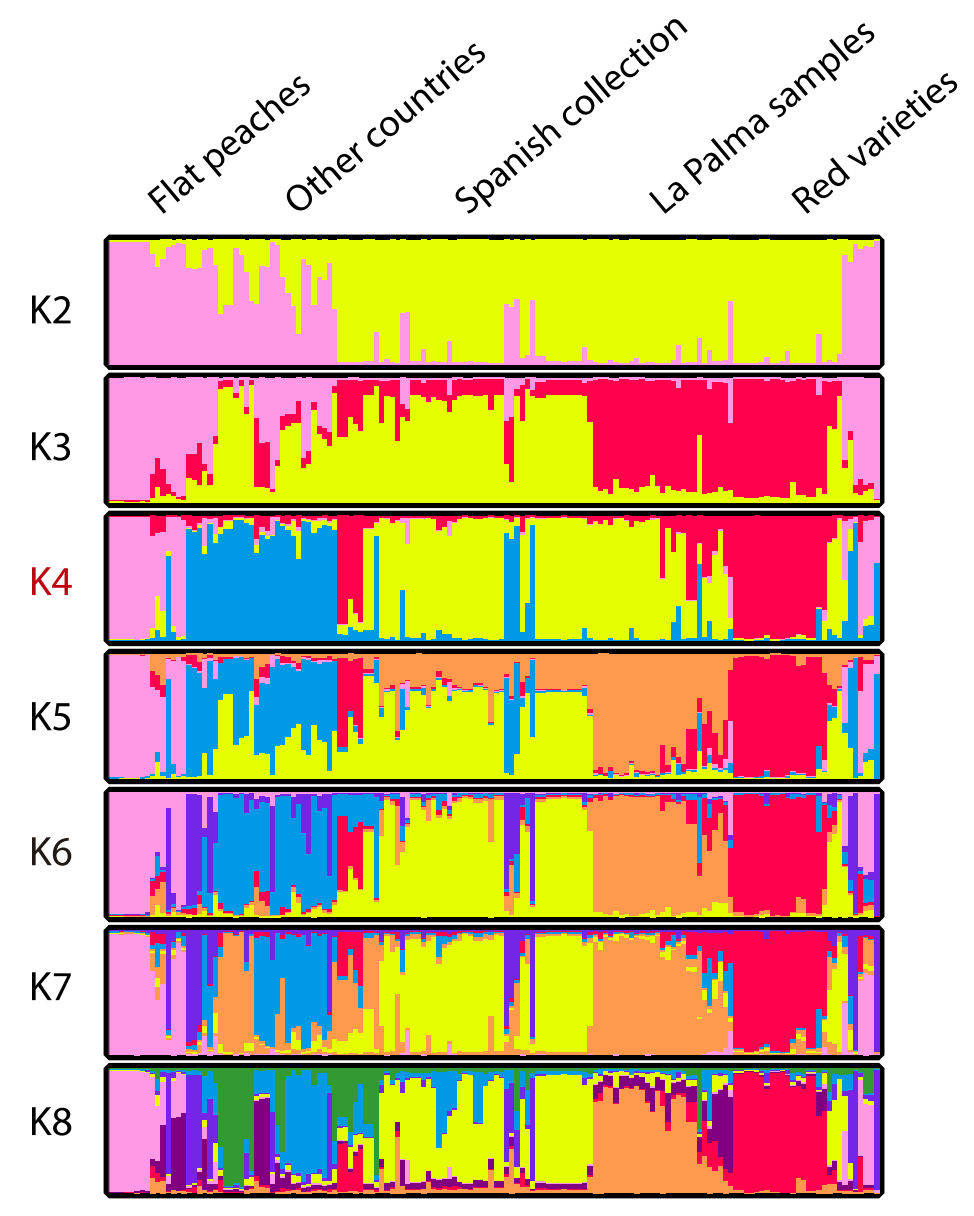

Figure 4. Structure results of the peach samples analyzed with 50 repetitions (for $Q=10 \times 5$ repetitions) for $k=2$ to $k=8$. The number of populations assigned by Evanno (4) is highlighted in red.

\section{Discussion}

\subsection{La Palma Peach Diversity}

The 10 SSR loci used in this study were suitable to differentiate the analyzed samples, as in a previous work performed by Wünsch et al. [14] with the same molecular markers. The pool of samples prospected in La Palma had 28 genotypes, and could be grouped in different genotype profiles, 
and the UPGMA dendrogram and diversity index reflected low variability. The analyses performed showed that La Palma samples are genetically very close, probably due to crossing and propagation by seeds from a limited number of original genotypes. The most common genotype 'Gent1' may have been propagated by grafting, and could be the most widespread genotype in the island in the past. The genotype profiles represented by only one sample could have been generated by seed propagation, as result of outcrossing, specifically 'Gent4,' 'Genet5,' ‘Gent6,' 'Gent7,' 'Gent9,' 'Gent10,' 'Gent13,' 'Gent14,' 'Gent16,' ‘Gent18,' 'Gent19,' 'Gent20,' 'Gent21,' 'Gent22,' 'Gent24,' 'Gent25,' or 'Gent 27.' These results point out that sexual reproduction and propagation were usual practices. At the same time, some exclusive profiles could have been introduced later as 'Gent28,' because they are close to Italian varieties, in the long branch, and far from the main group of local La Palma accessions, as can be seen in the NJ tree. Other genotype profiles such as 'Gent17' (de Corazón Colorao) and 'Gent 26' (Negra or Negra Palmera), which have preserved local names, could indeed be local varieties, so they must be taken into account for conservation. The intense prospection performed to find local peach varieties trees included different altitudes, from 126 to 993 masl, which means wide adaptability to diverse environmental conditions of this species. In fact, some genotypes are cultivated at different altitudes. Some samples were obtained at low-altitude localities with a low number of chilling hours and they could be of high interest to select varieties adapted to warmer winter conditions. The results obtained should be taken into account to establish ex situ peach collections.

\subsection{Comparison of the Diversity of La Palma Peach Accessions with Those from Other Origins}

The number of alleles per locus was higher than those reported by Wünsch et al. [14] for a Spanish local peach collection with the same SSR loci. This increase was probably due to the introduction of accessions from other countries, with higher diversity. Moreover, Wünsch et al. [14] used agarose gel electrophoresis to separate the PCR resulting bands, and the present work was performed with capillary electrophoresis, a more sensitive technique to detect small variations in band size. Comparison with other diversity studies in peach is more difficult due to the different number and sequence of the SSR loci. Thus, Aranzana et al. [30] obtained a higher number of alleles per locus using 50 SSR in 224 peach and nectarine cultivars; a similar higher number of alleles were reported by Bouhadida et al. [15] using 15 SSR in 94 peach varieties, but with only three of the SSR loci used in this work.

The comparison between the established populations showed different diversity indices, and the results obtained showed that the accessions from the group of other countries were the most diverse followed by the accessions of the Spanish collection. The lowest values obtained in the samples from La Palma were probably due to its geographic isolation and hybridization processes among a limited number of initial genotypes. In all cases, $\mathrm{H}_{\mathrm{e}}$ was higher than $\mathrm{H}_{\mathrm{o}}$ reflecting a deficiency of heterozygotes, which could be explained by selection or genetic drift processes. This is corroborated by the Fis Wright index as it is positive in all cases especially for La Palma, indicating a high rate of inbreeding. The pairwise Fst matrix indicated that population differentiation was small between Spain and other countries (0.02) and Spain and La Palma (0.038), while it was moderate among other countries and La Palma (0.091). The finding of some private alleles in La Palma local peaches compared to other populations, specifically the population of Spain, could indicate a different entry of plant material.

The comparison of peaches prospected in La Palma with samples from the collection of local varieties in Spain and accessions from eight other countries helped to relate La Palma samples with peaches from other places, contributing to understand the possible origin of these local genotypes. The reduced diversity among La Palma samples indicates that few ancient varieties arrived to the island, and that a posterior hybridization process took place. This is shown in the grouping of most accessions in one group in the NJ dendrogram. This is also reflected in the population analysis, with $k>4$ in STRUCTURE La Palma and the mainland Spanish samples grouped in one population, suggesting a close proximity between them. The close aggrupation, shown by the Bayesian analysis and the NJ tree, between Spanish local varieties 'Generoso,' 'Calanda Sonrosado,' and 'Amarillo Octubre' and most La Palma genotypes (17 out of 28 ) could be pointing out the mainland Spanish origin of these La Palma 
varieties. La Palma red variety 'Gent26' was also related to Spanish red varieties that were considered as a separate population; so additional plant material introduction from the Iberian Peninsula is likely. La Palma genotype profiles 'Gent15,' 'Gent16,' and 'Gent17' are also close to Spanish varieties, as the variety Duraznillo, a variety whose name is very similar to the common name for peach in the Canary Islands and Latin America (durazno). In addition, these genotypes were included in the same branch with four samples from Bolivia, which could be the result of the movement of genetic material from the islands or Iberian Peninsula to the New World and/or vice versa. There are other genotype profiles such as 'Gent13,' 'Gent23,' 'Gent24,' and 'Gent28,' with different positions in the dendrogram, which could represent more recently introduced genetic material. 'Genet24' may have arrived from Spain or from other countries due to its genetic proximity to Italian varieties. 'Gent23' had the same genetic profile as 'Keimoes,' a variety from South Africa, and 'Gent28' named Venezolano, referring to Venezuela, could have arrived from that American country. The Canary Islands in general, and La Palma in particular, had important trade harbors in the past that could facilitate the entry of plant material from other countries. In fact, La Palma during the last century suffered an important emigration to American countries such as Venezuela, which drove cultural exchange that can also be reflected in the plant species and varieties movement [20].

\subsection{Genetic Structure}

Samples were initially classified in three populations depending on the geographical origin except for the group named "other countries," which included accessions outside Spain, mainly from Italy and Bolivia. After NJ and STRUCTURE analysis, a relation with this initial grouping was confirmed, although the Spanish collection also included La Palma samples, and flat and red peach varieties formed a separated group at $k=4$, the optimal number of populations assigned by Evanno. One of these groups contained flat peaches. This type of peach was also separated from other types in previous works $[14,15,30]$. The second group contained the red color varieties, which indicates a possible relationship of color and genotype. In this group, some yellow varieties were also present. Grouping of red varieties was also found before [14,15] and, in fact, genes related to fruit peach skin color have been found showing a differentiation between peach varieties according to their skin color [4]. This trait was probably selected recently in the course of peach improvement [4].

Both NJ and STRUCTURE analyses showed a close relationship between La Palma and Spain mainland samples, which suggested the main origin of La Palma samples from the Iberian Peninsula. Similar results were obtained for other fruit tree species for which genetic diversity in La Palma was studied and compared to that in Spain, like almond [50], apple [51], chestnut [52], apple [53], or grapevine [54]. The rest of the accessions from La Palma that grouped in other clusters could be due to more recent plant introductions. These results open the possibility to study the genetic diversity and relationship of peach local varieties from other Canary Islands where this fruit tree is also grown.

\section{Conclusions}

In this work, La Palma local peach varieties have been characterized using molecular markers. A comparison of La Palma samples with a Spanish local peach collection and genotypes from eight additional countries provided information about the relationship between them. Results showed that the most possible origin of most of the local peaches from La Palma is the Iberian Peninsula, although the genetic relationship with accessions from other countries suggest the possible additional arrival of plant material from other origins. The low genetic diversity among La Palma samples points out that La Palma local varieties were developed from a low number of initial varieties that were intercrossed, and the local selection made by farmers for centuries has resulted in an interesting pool of varieties adapted to different climatic conditions, some of them with low chilling requirements. The abandonment of this crop in La Palma and other islands in the Canaries makes its conservation necessary to conserve interesting genetic resources, which could be very useful for breeding programs in the current context of climate change. 
Supplementary Materials: The following are available online at http://www.mdpi.com/2073-4395/10/4/457/s1. Table S1: Samples prospected in La Palma grouped by genotype profile, and showing location, altitude, and local name, Table S2: Samples from the Spanish collection and samples from other countries. Indicating accessions as local name, country, and locality.

Author Contributions: J.I.H. and V.P. designed the experiments. V.P. and D.A. conducted the experiments. V.P. and N.L. analyzed and interpreted the data, and V.P., N.L., A.W. and J.I.H. wrote the paper. All authors have read and agreed to the published version of the manuscript.

Funding: This work has been funded by the Ministerio de Economía y Competitividad-European Development Fund, European Union (AGL2016-77267-R) and INIA (RFP2015-00015-00-00 ‘Banco de recursos fitogenéticos de frutales del CITA de Aragón'). V.P. was supported by a Cabildo de La Palma-CSIC postdoc contract. N.L. is funded by the Mexican Governement through the Mexican Agency for International Development Cooperation.

Acknowledgments: We thank Neftalí Castro and Arnulio López Guerra of the CAP (Centro de Agrodiversidad de La Palma) and Agronomic Agencies of La Palma to help collect samples. Also, we thank Yolanda Verdún for the laboratory work, Manuel Cárdenas to help with the maps and Jose Manuel Alonso for helpful information on peach varieties.

Conflicts of Interest: The authors declare no conflict of interests.

\section{References}

1. Faust, M.; Timon, B. Origin and dissemination of peach. Hortic. Rev. 1995, 17, 331-379.

2. Huang, H.W.; Cheng, Z.P.; Zhang, Z.H.; Wang, Y. History of cultivation and trends in China. In The Peach: Botany, Production and Uses; Layne, D.R., Ed.; CABI: Wallingford, UK, 2008; pp. 37-60.

3. Zheng, Y.; Crawford, G.; Chen, X. Archaeological evidence for peach (Prunus persica) cultivation and domestication in China. PLoS ONE 2014, 9, e106595. [CrossRef]

4. Yu, Y.; Fu, J.; Xu, Y.; Zhang, J.; Ren, F.; Zhao, H.; Tian, S.; Guo, W.; Tu, X.; Zhao, J.; et al. Genome re-sequencing reveals the evolutionary history of peach fruit edibility. Nature communications 2018, 9, 5404. [CrossRef]

5. FAOSTAT. Available online: http://www.fao.org/faostat/en/\#data (accessed on 13 February 2020).

6. Hesse, C.O. Peaches. In Advances in Fruit Breeding; Janick, J., Moore, J.N., Eds.; Purdue University Press: West Lafayette, IN, USA, 1975; pp. 285-335.

7. Baird, W.V.; Ballard, R.E.; Rajapakse, S.; Abbott, A.G. Progress in Prunus mapping and application of molecular markers to germplasm improvement. HortSci 1996, 31, 1099-1106. [CrossRef]

8. Li, T.H.; Li, Y.X.; Li, Z.C.; Zhang, H.L.; Qi, Y.W.; Wang, T. Simple sequence repeat analysis of genetic diversity in primary core collection of peach (Prunus persica). J. Integr. Plant Biol. 2008, 50, 102-110. [CrossRef] [PubMed]

9. Xie, R.; Li, X.; Chai, M.; Song, L.; Jia, H.; Wu, D.; Chen, M.; Chen, K.; Aranzana, M.J.; Gao, Z. Evaluation of the genetic diversity of Asian peach accessions using a selected set of SSR markers. Sci. Hortic 2010, 125, 622-629. [CrossRef]

10. Li, X.; Meng, X.; Jia, H.; Yu, M.; Ma, R.; Wang, L.; Cao, K.; Shen, Z.; Niu, L.; Tian, J.; et al. Peach genetic resources: Diversity, population structure and linkage disequilibrium. BMC Genet. 2013, 14, 84. [CrossRef] [PubMed]

11. Aranzana, J.M.; Carbó, J.; Arús, P. Microsatellite variability in peach [Prunus persica (L.) Batsch]: Cultivar identification, marker mutation, pedigree inferences and population structure. Theor. Appl. Genet 2003, 106, 1341-1352. [CrossRef] [PubMed]

12. The International Peach Genome Initiative. The high-quality draft genome of peach (Prunus persica) identifies unique patterns of genetic diversity, domestication and genome evolution. Nat. Genet. 2013, 45, 487-494. [CrossRef]

13. Martín, C.; Herrero, M.; Hormaza, J.I. Molecular characterization of apricot germplasm from an old stone collection. PLoS ONE 2011, 6, e23979. [CrossRef]

14. Wünsch, A.; Carrera, M.; Hormaza, J.I. Molecular characterization of local Spanish peach [Prunus persica (L.) Batsch] germplasm. Genet. Resour. Crop Evol. 2006, 53, 925-932. [CrossRef]

15. Bouhadida, M.; Moreno, M.A.; Gonzalo, M.J.; Alonso, J.M.; Gogorcena, Y. Genetic variability of introduced and local Spanish peach cultivars determined by SSR markers. Tree Genet. Genomes 2011, 7, $257-270$. [CrossRef] 
16. Larranaga, N.; Albertazzi, F.J.; Fontecha, G.; Palmieri, M.; Rainer, H.; van Zonneveld, M.; Hormaza, J.I. A Mesoamerican origin of cherimoya (Annona cherimola Mill.). Implications for the conservation of plant genetic resources. Mol. Ecol. 2017, 26, 4116-4130. [CrossRef] [PubMed]

17. Hammer, K.; Arrowsmith, N.; Gladis, T. Agrobiodiversity with emphasis on plant genetic resources. Naturwissenschaften 2003, 90, 241-250. [CrossRef]

18. Santana-Pérez, G. Comercio palmero en el tránsito del siglo XVI al XVII: Tras el signo del ataque de Drake. Tebeto: Anuario del Archivo Histórico Insular de Fuerteventura 2014, 7, 73-89. (In Spanish)

19. Mendizabal, I.; Sandoval, K.; Berniell-Lee, G.; Calafell, F.; Salas, A.; Martínez-Fuentes, A.; Comas, D. Genetic origin, admixture, and asymmetry in maternal and paternal human lineages in Cuba. BMC Evol. Biol. 2008, 8, 213. [CrossRef]

20. Gómez-Carballa, A.; Ignacio-Veiga, A.; Álvarez-Iglesias, V.; Pastoriza-Mourelle, A.; Ruíz, Y.; Pineda, L.; Carracedo, A.; Salas, A. A melting pot of multicontinental mtDNA lineages in admixed Venesuelans. Am. J. Phys. Anthropol. 2012, 147, 78-87. [CrossRef]

21. Suárez-Bosa, M.; Suárez-Viera, F. Emigration and Canary Islands entrepreneurship in Cuba, 1850-1950. Secuencia 2013, 87, 97-126. (In Spanish)

22. Brito, W.R. La Agricultura en la isla de La Palma; Instituto de Estudios Canarios: La Laguna: Tenerife, Spain, 1982. (In Spanish)

23. Viera y Clavijo, J.D. Diccionario de Historia Natural de las Islas Canarias; Real Sociedad de Amigos del País de Las Palmas de Gran Canaria: Gran Canaria, Spain, 1866. (In Spanish)

24. Herrero, J. Cartografía de Frutales de Hueso y Pepita; Estación Experimental de Aula Dei (EEAD-CSIC): Zaragoza, Spain, 1964. (In Spanish)

25. ISTAC. Available online: http://www.gobiernodecanarias.org/istac/jaxi-istac/tabla.do (accessed on 9 December 2019).

26. Varshney, R.K.; Graner, A.; Sorrells, M.E. Genomics-assisted breeding for crop improvement. Trends Plant Sci. 2005, 10, 621-630. [CrossRef]

27. Cheng, Z.; Huang, H. SSR fingerprinting Chinese peach cultivars and landraces (Prunus persica) and analysis of their genetic relationships. Sci. Hortic. 2009, 120, 188-193. [CrossRef]

28. Bouhadida, M.; Casas, A.M.; Moreno, M.A.; Gogorcena, Y. Molecular characterization of Miraflores peach variety and relatives using SSRs. Sci. Hortic. 2007, 111, 140-145. [CrossRef]

29. Testolin, R.; Marrazzo, T.; Cipriani, G.; Quarta, R.; Verde, I.; Dettori, M.T.; Pancaldi, M.; Sansavini, S. Microsatellite DNA in peach (Prunus persica L. Batsch) and its use in fingerprinting and testing the genetic origin of cultivars. Genome 2000, 43, 512-520. [CrossRef] [PubMed]

30. Aranzana, M.J.; Abbassi, E.K.; Howad, W.; Arús, P. Genetic variation, population structure and linkage disequilibrium in peach commercial varieties. BMC Genet. 2010, 11, 69. [CrossRef] [PubMed]

31. Yoon, J.; Liu, D.; Song, W.; Liu, W.; Zhang, A.; Li, S. Genetic diversity and ecogeographical phylogenetic relationships among peach and nectarine cultivars based on simple sequence repeat (SSR) markers. J. Am. Soc. Hortic. Sci. 2006, 131, 513-521. [CrossRef]

32. Hormaza, J.I. Molecular characterization and similarity relationships among apricot (Prunus armeniaca L.) genotypes using simple sequence repeats. Theor. Appl. Genet. 2002, 104, 321-328. [CrossRef]

33. QGIS Development Team. Version 2.8.1-Wien. QGIS Geographic Information System. Open Source Geospatial Foundation Project. Available online: http://www.qgis.org/ (accessed on 23 February 2020).

34. Rohlf, F.J. NTSYS-PC: Numerical Taxonomy and Multivariable Analysis System-Version 2.0; Exeter Software: New York, NY, USA, 1993.

35. Nei, M.; Li, W.H. Mathematical model for studying genetic variation in terms of restriction endonucleases. Proc. Natl. Acad. Sci. USA 1979, 76, 5269-5273. [CrossRef]

36. Wright, S. The genetical structure of populations. Ann. Eugen. 1949, 15, 323-354. [CrossRef]

37. Jombart, T. adegenet: A R package for the multivariate analysis of genetic markers. Bioinformatics 2008, 24, 1403-1405. [CrossRef]

38. Jombart, T.; Ahmed, I. adegenet 1.3-1: New tools for the analysis of genome-wide SNP data. Bioinformatics 2011, 27, 3070-3071. [CrossRef]

39. Adamack, A.T.; Gruber, B. PopGenReport: Simplifying basic population genetic analyses in R. Methods Ecol. Evol. 2014, 5, 384-387. [CrossRef] 
40. Gruber, B.; Adamack, A.T. Landgenreport: A new R function to simplify landscape genetic analysis using resistance surface layers. Mol. Ecol. Resour. 2015, 15, 1172-1178. [CrossRef] [PubMed]

41. Fig Tree. Available online: http://tree.bio.ed.ac.uk/software/figtree/ (accessed on 23 March 2020).

42. Hubisz, M.J.; Falush, D.; Stephens, M.; Pritchard, J.K. Inferring weak population structure with the assistance of sample group information. Mol. Ecol. Resour. 2009, 9, 1322-1332. [CrossRef] [PubMed]

43. Evanno, G.; Regnaut, S.; Goudet, J. Detecting the number of clusters of individuals using the software STRUCTURE: A simulation study. Mol. Ecol. 2005, 14, 2611-2620. [CrossRef] [PubMed]

44. Earl, D.A.; von Holdt, B.M. Structure Harvester: A website and program for visualizing STRUCTURE output and implementing the Evanno method. Conserv. Genet. Resour. 2012, 4, 359-361. [CrossRef]

45. Jakobsson, M.; Rosenberg, N.A. CLUMPP: A cluster matching and permutation program for dealing with label switching and multimodality in analysis of population structure. Bioinformatics 2007, 23, 1801-1806. [CrossRef]

46. Rosenberg, N.A. DISTRUCT: A program for the graphical display of population structure. Mol. Ecol. Notes 2004, 4, 137-138. [CrossRef]

47. Sosinski, B.; Gannavarapu, M.; Hager, L.D.; Beck, L.E.; King, G.J.; Ryder, C.D.; Rajapakse, S.; Baird, W.V.; Ballard, R.E.; Abbott, A.G. Characterization of microsatellite markers in peach [Prunus persica (L.) Batsch]. Theor. Appl. Genet. 2000, 101, 421-428. [CrossRef]

48. Cipriani, G.; Lot, G.; Huang, W.G.; Marrazzo, M.T.; Peterlunger, E.; Testolin, R. AC/GT and AG/CT microsatellite repeats in peach [Prunus persica (L) Batsch]: Isolation, characterisation and cross-species amplification in Prunus. Theor. Appl. Genet. 1999, 99, 65-72. [CrossRef]

49. Aranzana, M.J.; Garcia-Mas, J.; Carbo, J.; Arús, P. Development and variability analysis of microsatellite markers in peach. Plant Breed. 2002, 121, 87-92. [CrossRef]

50. Padilla, G.; Socias i Company, R.; Ordás, A. Molecular characterization of almond accessions from the island of La Palma (Canary Islands, Spain) using SSR markers. Plant Genet. Resour. 2014, 12, 323-329. [CrossRef]

51. Pereira-Lorenzo, S.; Ramos-Cabrer, A.M.; Gonzalez-Diaz, A.J.; Diaz-Hernandez, M.B. Genetic assessment of local apple cultivars from La Palma, Spain, using simple sequence repeats (SSRs). Sci. Hortic. 2008, 117, 160-166. [CrossRef]

52. Pereira-Lorenzo, S.; Costa, R.M.L.; Ramos-Cabrer, A.M.; Ciordia-Ara, M.; Ribeiro, C.A.M.; Borges, O.; Barreneche, T. Chestnut cultivar diversification process in the Iberian Peninsula, Canary Islands, and Azores. Genome 2011, 54, 301-315. [CrossRef] [PubMed]

53. Pereira-Lorenzo, S.; Ramos-Cabrer, A.M.; Ferreira, V.; Díaz-Hernández, M.B.; Carnide, V.; Pinto-Carnide, O.; Rodrigues, R.; Velázquez-Barrera, M.E.; Rios-Mesa, D.; Ascasíbar-Errasti, J.; et al. Genetic diversity and core collection of Malus $\times$ domestica in northwestern Spain, Portugal and the Canary Islands by SSRs. Sci. Hortic. 2018, 240, 49-56. [CrossRef]

54. Marsal, G.; Méndez, J.J.; Mateo, J.M.; Ferrer, S.; Canals, J.M.; Zamora, F.; Fort, F. Molecular characterization of Vitis vinifera L. local cultivars from volcanic areas (Canary Islands and Madeira) using SSR markers. OENO One 2019, 53. [CrossRef]

(C) 2020 by the authors. Licensee MDPI, Basel, Switzerland. This article is an open access article distributed under the terms and conditions of the Creative Commons Attribution (CC BY) license (http://creativecommons.org/licenses/by/4.0/). 